\title{
Habilidade competitiva e biológica do consórcio beterraba com caupi-hortaliça proveniente de adubação verde e de $\operatorname{arranjos~espaciais~}^{1}$
}

\author{
Edilson Carvalho de Morais ${ }^{2}$, Jailma Suerda Silva de Lima ${ }^{3}$, Francisco Bezerra Neto ${ }^{3}$, \\ Josimar Nogueora da Silva ${ }^{3 *}$, Renato Leandro Costa Nunes ${ }^{3}$, Paulo Cássio Alves Linhares ${ }^{4}$
}

$10.1590 / 0034-737 X 201865050008$

\section{RESUMO}

O objetivo deste trabalho foi avaliar as habilidades competitiva e biológica do consórcio de beterraba com caupihortaliça, em função de quantidades de biomassa de flor-de-seda incorporada ao solo e de arranjos espaciais. $\mathrm{O}$ delineamento experimental utilizado foi o de blocos completos casualizados, em esquema fatorial 4 x 3 , compreendendo a combinação de quatro quantidades de flor-de-seda incorporadas ao solo $\left(20,35,50\right.$ e 65 t ha $^{-1}$ de matéria seca) e três arranjos espaciais, entre fileiras de plantas, das culturas componentes do consórcio (2:2, 3:3 e 4:4). Foram avaliados os índices de competição: o de perda ou de ganho real de rendimento, o de superação e o coeficiente relativo populacional e de razão competitiva. Os índices de eficiência biológica avaliados foram: uso eficiente da terra, da beterraba e do caupi-hortaliça. A cultura do caupi-hortaliça apresentou maior ganho de produção e melhor capacidade de competição do que a cultura da beterraba, e os arranjos espaciais não influenciaram o desempenho produtivo das culturas. A maior viabilidade biológica do consórcio de beterraba com caupi-hortaliça foi obtida na quantidade de $65 \mathrm{t} \mathrm{ha}^{-1} \mathrm{de} \mathrm{biomassa}$ de flor-de-seda incorporada ao solo. Não houve influência dos arranjos espaciais na habilidade competitiva e na viabilidade agroeconômica do consórcio de beterraba com caupi-hortaliça.

Palavras-chave: cultivo consorciado; adubação verde; arranjos espaciais.

\section{ABSTRACT \\ Competitive and biological ability of beet and cowpea vegetable intercropping deriving from green manuring and spatial arrangements}

The objective of this work was to evaluate the competitive and biological abilities of the beet and cowpea vegetable intercropping as a function of biomass amounts of roostertree incorporated into the soil and of spatial arrangements. The experimental design was in completely randomized blocks in a $4 \times 3$ factorial scheme, comprising the combination of four amounts of roostertree biomass $\left(20,35,50\right.$, and $65 \mathrm{t} \mathrm{ha}^{-1}$ on dry matter) and three spatial arrangements between plant rows of the component crops of the intercropping (2:2, 3:3, and 4:4). The competition indexes were evaluated: actual yield gain or loss, aggressivity, relative crowding coefficient, and competitive ratio. The biological efficiency indexes evaluated were: land equivalent ratios for the system, beet, and cowpea. It was verified that the cowpea vegetable crop obtained higher production gain and a better competition capacity than the beet crop in the established intercropping, and that spatial arrangements did not interfere with the productive performance of the crops. The cowpea vegetable crop was more competitive than the beet in the intercropping system. The highest biological viability of the beet and cowpea vegetable intercropping was obtained in the amount of $65 \mathrm{tha}^{-1}$ of roostertree biomass incorporated into the soil. There was no influence of spatial arrangements on the competitive ability and agroeconomic viability of beet and cowpea vegetable intercropping.

Keywords: intercropping system; green manuring; spatial arrangements.

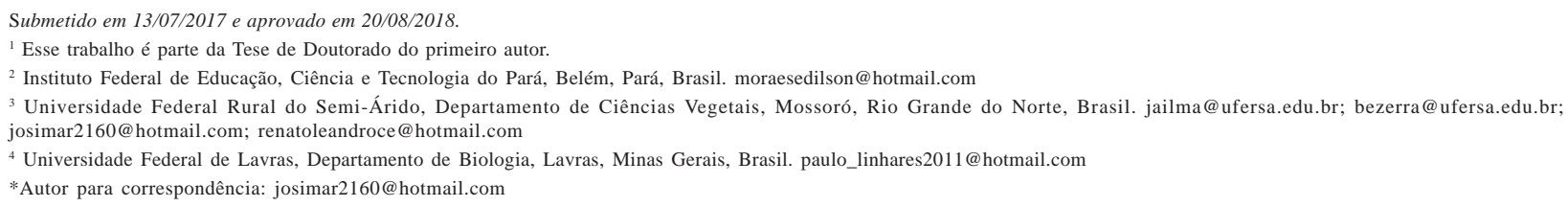




\section{INTRODUÇÃO}

Os olericultores têm empregado várias tecnologias em busca do aumento da produtividade das culturas, para atender a demanda do mercado consumidor. Dentre os sistemas que vêm sendo utilizados com sucesso, encontra-se o do cultivo consorciado, que, ao ser realizado em sistemas agroecológicos, apresenta ganhos de produtividade e de valores nutricional, econômico e ambiental (Oliveira et al., 2004), por meio da exploração eficiente dos fatores de produção (Bezerra Neto et al., 2007).

Todavia, para se obter ganhos em produtividade para as culturas, é essencial o uso de técnicas agronômicas adequadas (Silva et al., 2017), dentre as quais se destacam a adubação verde, que aumenta a percentagem de matéria orgânica do solo (Bezerra Neto et al., 2014), melhorando sua estrutura, arejamento e capacidade de armazenamento de água (Silva et al., 2013), como também, o uso de melhores arranjos espaciais entre as culturas componentes.

No Brasil, espécies da família das leguminosas são as mais utilizadas como adubo verde. Porém, em se tratando de semiárido nordestino, plantas espontâneas ou exóticas, com alto potencial de produção de biomassa, vêm-se destacando como fontes de adubo verde, dentre as quais apresenta-se a flor-de-seda (Calotropis procera (Ait.) R.Br.). No Estado do Rio Grande do Norte, essa espécie vem apresentando aumento na produtividade de hortaliças, como maior produção comercial de cenoura $(33,06 \mathrm{t}$ $\mathrm{ha}^{-1}$ ) consorciada com feijão-caupi, que obteve rendimento de grãos verdes de 3,69 $\mathrm{t} \mathrm{ha}^{-1}$, com o uso de 26,31 e 61 $\mathrm{t} \mathrm{ha}^{-1}$, respectivamente, de flor-de-seda incorporada ao solo (Favacho et al., 2017). Além de ser adaptada às condições edafoclimáticas da região, apresenta alta produção de fitomassa (Linhares et al., 2012), com teores de nutrientes: nitrogênio, 15,3 $\mathrm{g} \mathrm{kg}^{-1}$; fósforo, $4,0 \mathrm{~g} \mathrm{~kg}^{-1}$; potássio, $15,7 \mathrm{~g} \mathrm{~kg}^{-1}$; cálcio, 9,3 $\mathrm{g} \mathrm{kg}^{-1}$; magnésio, 7,03 $\mathrm{g} \mathrm{kg}^{-1}$, e relação carbono/nitrogênio de 20:1 (Vieira et al., 2018), o que a caracteriza como planta com alto potencial de utilização como adubo verde.

Por sua vez, os diferentes arranjos espaciais podem delinear a distribuição das culturas associadas no campo, de modo a reduzir a competição intra e interespecífica pelos recursos do ambiente (Pinto et al., 2012), podendo contribuir para o aumento dos rendimentos das culturas em consórcio (Pivetta et al., 2012).

Dessa forma, faz-se necessário o conhecimento de índices de avaliação do sistema consorciado que proporcionem melhor entendimento do mecanismo da habilidade competitiva entre as culturas componentes e a eficiência biológica do sistema consorciado (Pinto et al., 2012; Cecílio Filho et al., 2015, Bezerra Neto et al., 2012). Dentre esses índices, destacam-se o coeficiente relativo populacional, o de perda ou ganho real de rendimento (Cecílio Filho et al., 2015; Cecílio Filho et al., 2013), o coeficiente de competição (Batista et al., 2016), o índice de agressividade e o índice de uso eficiente da terra (Lima et al., 2008).

Neste sentido, surge a necessidade de desenvolverem-se trabalhos que possam avaliar a habilidade competitiva entre as culturas componentes e a eficiência biológica do sistema consorciado. Assim sendo, o objetivo deste trabalho foi avaliar a habilidade competitiva das culturas componentes e a eficiência biológica do consórcio de beterraba com caupi-hortaliça, em função de quantidades de flor-de-seda incorporadas ao solo e de arranjos espaciais.

\section{MATERIAL E MÉTODOS}

O estudo foi realizado em condições de campo, na Fazenda Experimental Rafael Fernandes, da Universidade Federal Rural do Semi-Árido (UFERSA), Mossoró, RN, de junho a dezembro de 2014. No período experimental, a precipitação pluviométrica foi de $0 \mathrm{~mm}$; as temperaturas máximas, média e mínima foram de $33,4^{\circ} \mathrm{C}, 28,5^{\circ} \mathrm{C}$ e 23,03 ${ }^{\circ} \mathrm{C}$, respectivamente, a umidade relativa do ar de $62 \%$ e a radiação solar de $901 \mathrm{kj} \mathrm{m}^{-2}$.

Foram coletadas amostras de solo, na camada de 0-20 $\mathrm{cm}$, antes da instalação do experimento em campo, analisadas no Laboratório de Química e Fertilidade do Solo e Nutrição de Plantas, da UFERSA, obtendo-se os seguintes resultados: $\mathrm{pH}=6,12, \mathrm{P}=3,75 \mathrm{mg} \mathrm{dm}^{-3}, \mathrm{~K}=70,82 \mathrm{mg}$ $\mathrm{dm}^{-3}, \mathrm{Ca}=1,98 \mathrm{cmol}_{\mathrm{c}} \mathrm{dm}^{-3}, \mathrm{Mg}=0,68 \mathrm{cmol}_{\mathrm{c}} \mathrm{dm}^{-3}, \mathrm{Na}=7,8$ $\mathrm{mg} \mathrm{dm}{ }^{-3}, \mathrm{CE}=0,18 \mathrm{dS} \mathrm{m}^{-1}$, M.O. $=7,82 \mathrm{~g} \mathrm{~kg}^{-1}, \mathrm{SB}=2,88 \mathrm{cmol}_{\circ}$ $\mathrm{dm}^{-3}, \mathrm{CTC}=3,48 \mathrm{cmol}_{\mathrm{c}} \mathrm{dm}^{-3}, \mathrm{PST}=1,0 \%, \mathrm{t}=2,88 \mathrm{cmol}_{\mathrm{c}} \mathrm{dm}^{-3}$ $\mathrm{e} \mathrm{V}=83 \%$.

O solo foi preparado por meio de limpeza mecânica da área com trator com arado acoplado, seguida de gradagem e levantamento dos canteiros, com retroencanteirador. Uma solarização foi realizada em pré-plantio durante 45 dias, conforme metodologia de Silva et al. (2006).

O delineamento experimental utilizado foi o de blocos casualizados, em esquema fatorial 4 x 3 , com quatro repetições. O primeiro fator foi constituído por quatro quantidades de biomassa seca de flor-de-seda incorporadas ao solo $\left(20,35,50\right.$ e $\left.65 \mathrm{t} \mathrm{ha}^{-1}\right)$ e, o segundo fator, por três arranjos espaciais de fileiras de plantas das culturas (2:2, 3:3 e 4:4) (Figura 1).

O cultivo consorciado constituiu-se de fileiras alternadas, de acordo com os arranjos espaciais utilizados, de beterraba e de caupi-hortaliça, com 50\% da área para cada cultura. Em cada parcela, foram plantadas fileirasbordadura de cada cultura, com 25 e dez plantas por metro linear na área útil da parcela, para a beterraba e o caupihortaliça, respectivamente, com uma planta por cova. 
As áreas totais das parcelas nos arranjos espaciais 2:2, 3:3 e 4:4 foram de 2,40,3,00 e 3,60 m² com áreas úteis de 1,00, 1,50 e 2,00 $\mathrm{m}^{2}$, com 50, 75 e 100 plantas de beterraba e 20,30 e 40 plantas de caupi-hortaliça, nos espaçamentos $0,25 \mathrm{~m} \mathrm{x}$ $0,04 \mathrm{~m} \mathrm{e} 0,25 \mathrm{~m}$ x 0,10 m, respectivamente (Figura 1 ).

Foram plantadas parcelas solteiras das hortaliças em estudo, para obtenção dos índices do consórcio. Para a beterraba, a área total da parcela foi de $1,44 \mathrm{~m}^{2}$, com área útil de $0,80 \mathrm{~m}^{2}$, no espaçamento $0,20 \mathrm{~m}$ x $0,10 \mathrm{~m}$. Para o caupi-hortaliça, a área total foi de $3,60 \mathrm{~m}^{2}$, com área útil de $2,00 \mathrm{~m}^{2}$, no espaçamento $0,50 \mathrm{~m}$ x 0,10 m. Ambas as culturas foram cultivadas de acordo com as populações de plantas recomendadas nos cultivos solteiros (Silva et al., 2011; Santos, 2011).

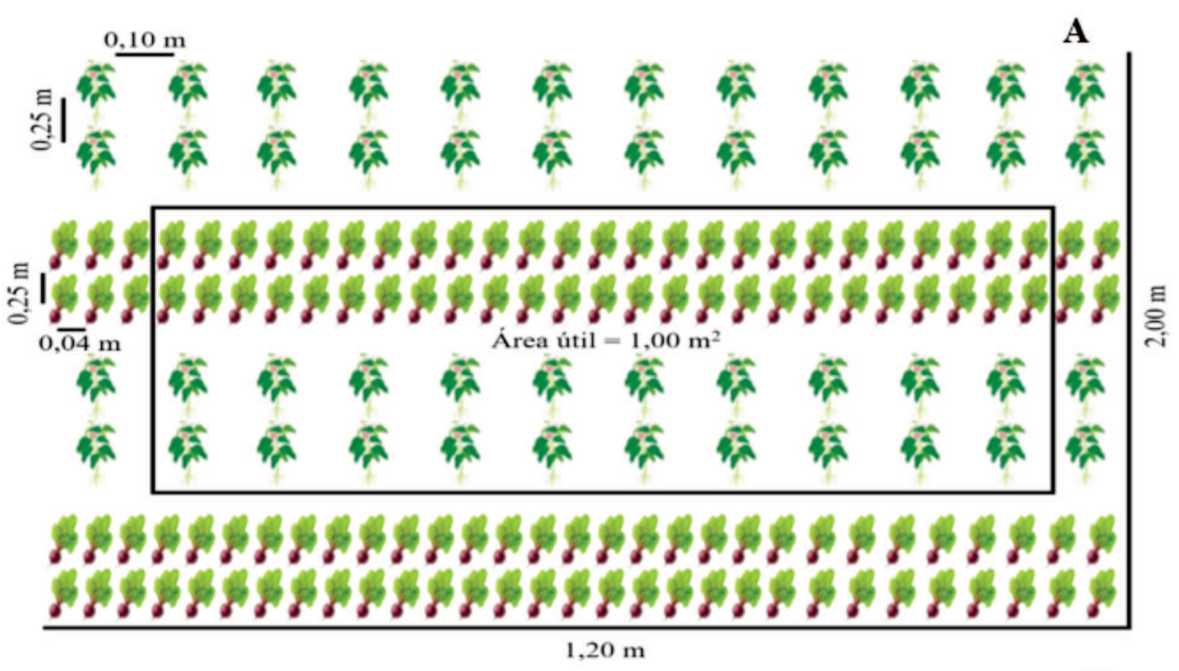

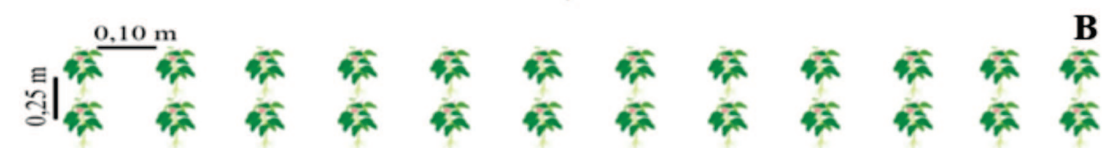

\&

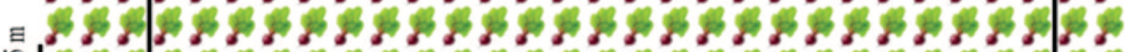

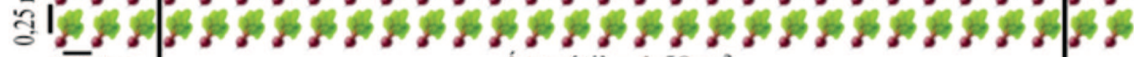

\begin{tabular}{|c|c|c|c|c|c|c|c|c|c|c|}
\hline$\frac{04 \mathrm{~m}}{\pi}$ & $\sqrt{x}$ & $\sqrt{x}$ & $2 x$ & \% & $\sqrt{2 \pi}$ & $\frac{10}{2}$ & $\sqrt{x}$ & क & $\sqrt{\pi}$ & 2h \\
\hline 标 & 27 & 标 & $2 \pi$ & \% & 27 & $7 \pi$ & $\pi$ & $\sqrt{\alpha}$ & 27 & $\sqrt{2 \pi}$ \\
\hline F & $6 x$ & 5 & 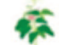 & 5 & $2 \pi$ & $4 \pi$ & $6 \pi$ & $2 \pi$ & 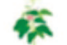 & 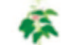 \\
\hline
\end{tabular}

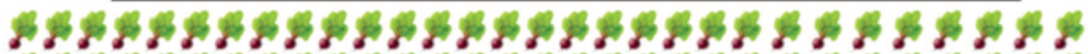

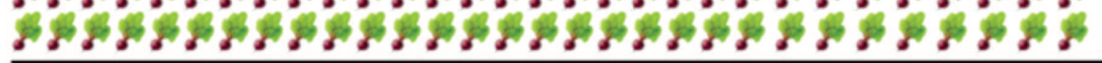

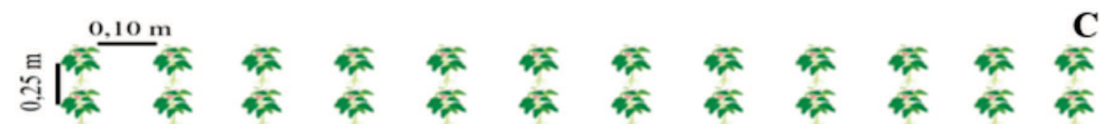

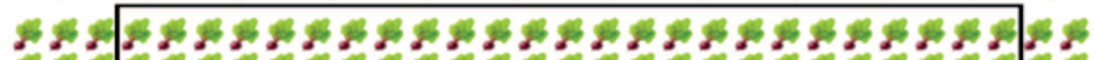

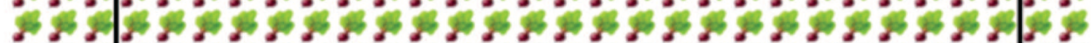

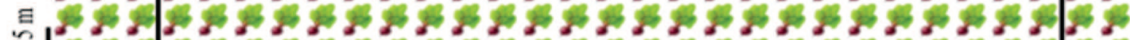

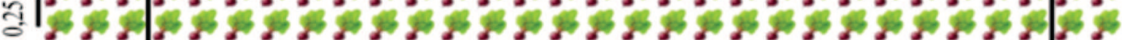

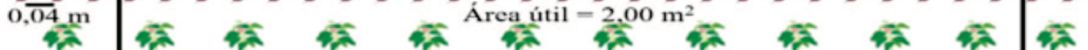

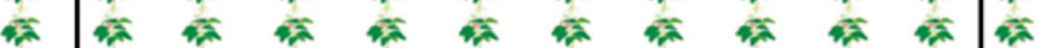

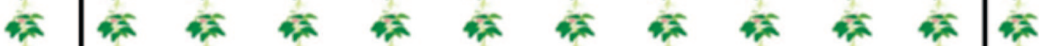

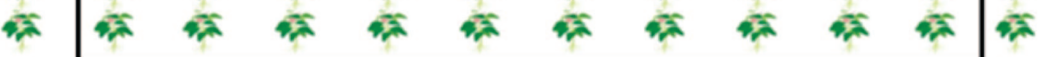

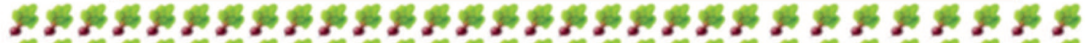

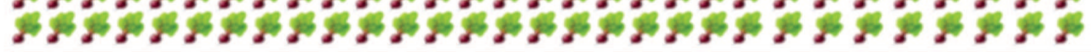

$1,20 \mathrm{~m}$

Figura 1: Representação gráfica das parcelas experimentais nos arranjos espaciais 2:2 (a), $3: 3$ (b) e 4:4 (c), no sistema de cultivo consorciado de beterraba ( 8 ) com caupi-hortaliça ( 
As plantas de flor-de-seda (Calotropis procera (Ait.) R.Br.) foram coletadas da vegetação nativa, nas proximidades de Mossoró, RN, conforme metodologia de Silva et al. (2013). Amostras desse material foram retiradas e encaminhadas ao Laboratório de Fertilidade do Solo e Nutrição de Plantas da UFERSA, para realização das análises químicas, obtendo-se os seguintes resultados: $\mathrm{N}=7,43 \mathrm{~g}$ $\mathrm{kg}^{-1} ; \mathrm{P}=0,91 \mathrm{~g} \mathrm{~kg}^{-1} ; \mathrm{K}=16,46 \mathrm{~g} \mathrm{~kg}^{-1} ; \mathrm{Ca}=8,2 \mathrm{~g} \mathrm{~kg}^{-1} ; \mathrm{Mg}=$ $7,35 \mathrm{~g} \mathrm{~kg}^{-1} ; \mathrm{Fe}=100,5 \mathrm{mg} \mathrm{kg}^{-1} ; \mathrm{Mn}=21,75 \mathrm{mg} \mathrm{kg}^{-1} ; \mathrm{Zn}=$ $37,88 \mathrm{mg} \mathrm{kg}^{-1} ; \mathrm{Cu}=3,85 \mathrm{mg} \mathrm{kg}^{-1} \mathrm{e} \mathrm{Na}=6085 \mathrm{mg} \mathrm{kg}^{-1}$.

A adubação foi parcelada em duas vezes, sendo 50\% das quantidades da flor-de-seda incorporadas aos 20 dias antes do plantio e, os 50\% restantes, aos 44 dias após o plantio. As quantidades de flor-de-seda utilizadas nos cultivos solteiros de beterraba e de caupi-hortaliça foram de 39 e 59 t ha $^{-1}$ (em base seca), respectivamente, conforme pesquisas anteriores (Andrade Filho, 2014; Vieira et al., 2018).

As irrigações foram efetuadas em dois turnos de rega (manhã e tarde), fornecendo-se, nos dois turnos, uma lâmina de água de aproximadamente $8 \mathrm{~mm} \mathrm{dia}^{-1}$ (Lima et al., 2010). Foram realizadas capinas manuais para o controle de plantas invasoras durante a condução do experimento, sempre que necessário. As cultivares de beterraba e de caupi-hortaliça plantados foram, respectivamente, a 'Early Wonder' e a BRS Itaim, adaptadas para o cultivo na região nordeste.

As semeaduras da beterraba e do caupi-hortaliça foram realizadas simultaneamente, no dia 08 de setembro de 2014 , em covas de aproximadamente $3 \mathrm{~cm}$ de profundidade, com três sementes por cova para a cultura da beterraba e duas sementes por cova para a do caupi-hortaliça. Aos 15 e sete dias após a semeadura (DAS), foram realizados os desbastes das plantas de beterraba e do caupihortaliça.

Aos 50 dias após a semeadura (DAS), foram marcadas aleatoriamente cinco plantas por fileira, em cada parcela experimental do caupi-hortaliça, com a sua colheita sendo realizada, logo após a marcação, aos 55 a 65 DAS, com quatro colheitas. A colheita da beterraba foi realizada aos 76 dias após a semeadura. Após a colheita, as plantas foram encaminhadas ao laboratório para análises.

As características mensuradas da beterraba e do caupihortaliça, para a avaliação dos índices foram: produtividade de raízes comerciais de beterraba livres de defeitos (rachaduras, bifurcações, nematoides e danos mecânicos) e produtividade de grãos verdes frescos de caupi-hortaliça.

Foram avaliados os índices de competição: os de perda ou de ganho real de rendimento, o de superação, o coeficiente relativo populacional e o de razão de competitiva. Os índices de eficiência biológica avaliados foram: os índices de uso eficiente da terra do sistema, da beterraba e do caupi-hortaliça.
Os índices de perda ou de ganho real de rendimento foram obtidos conforme metodologia proposta por (Cecílio Filho et al., 2013).

$P G R R_{b c h}=\left\{\frac{\left(U E T_{b} * 100\right)-1}{Z_{b c h}}+\frac{\left(U E T_{c h} * 100\right)-1}{Z_{c h b}}\right\}$, em que:

$\left(\mathrm{PGRR}_{\mathrm{bch}}\right), \mathrm{UET}_{\mathrm{b}}$ e $\mathrm{UET}_{\mathrm{ch}}=$ são a perda ou ganho atual de rendimento, que representam o uso eficiente da terra parcial da cultura da beterraba e do caupi-hortaliça;

$\mathrm{Z}_{\text {bch }}=$ representa a proporção de plantio da beterraba em consórcio com o caupi-hortaliça;

$\mathrm{Z}_{\mathrm{chb}}=$ representa a proporção de plantio do caupi-hortaliça em consórcio com a beterraba.

O índice de superação é um índice que serve para indicar quanto o acréscimo relativo de produção de uma cultura componente $\mathrm{b}$ (no caso a beterraba) é maior do que aquele da componente ch (caupi-hortaliça), em um sistema consorciado. Foi proposto por Oseni \& Aliyu (2010) para medir a dominância de uma cultura sobre a outra. Este índice é dado pelas seguintes expressões:

$I S_{b}=\left(\frac{Y_{b c h}}{Y_{b} Z_{b c h}}\right)-\left(\frac{Y_{c h b}}{Y_{c h} Z_{c h b}}\right)$ e $I S_{c h}=\left(\frac{Y_{c h b}}{Y_{c h} Z_{c h b}}\right)-\left(\frac{Y_{b c h}}{Y_{b} Z_{b c h}}\right)$, em que:

$\mathrm{IS}_{\mathrm{b}}$ e IS $\mathrm{Ih}_{\mathrm{ch}}=$ são os índices de superação da beterraba e do caupi-hortaliça;

$Y_{b c h}$ e $Y_{c h b}=$ são a produtividade comercial de raízes de beterraba e os rendimentos de grãos verdes do caupihortaliça na associação;

$\mathrm{Y}_{\mathrm{b}}$ e $\mathrm{Y}_{\mathrm{ch}=}$ são a produtividade comercial de raízes de beterraba e os rendimentos de grãos verdes do caupi-hortaliça em cultivo solteiro;

$\mathrm{Z}_{\text {bch }}$ = é a proporção do plantio da beterraba em consórcio com caupi-hortaliça;

$\mathrm{Z}_{\mathrm{chb}}=$ é a proporção do plantio do caupi-hortaliça em consórcio com beterraba.

O coeficiente relativo populacional é a medida de dominância de uma espécie sobre a outra na associação. Foi proposto (Cecílio Filho et al., 2015). É calculado pela seguinte expressão:

$K=K_{b} K_{c h} K_{b}=\frac{Y_{b c h} Z_{c h b}}{\left(Y_{b}-Z_{b c h}\right) Z_{b c h}}$ e $K_{c h}=\frac{Y_{c h b} Z_{b c h}}{\left(Y_{c h}-Z_{c h b}\right) Z_{c h b}} \quad$, em que:

$\mathrm{K}_{\mathrm{b}} \mathrm{e} \mathrm{K}_{\mathrm{ch}}=$ são os coeficientes relativos populacionais da beterraba e do caupi-hortaliça;

$\mathrm{Y}_{\mathrm{bch}}$ e $\mathrm{Y}_{\mathrm{chb}}=$ são a produtividade comercial de raízes de beterraba e o rendimento de grãos verdes do caupihortaliça, na associação; 
$\mathrm{Y}_{\mathrm{b}}$ e $\mathrm{Y}_{\mathrm{ch}}=$ é a produtividade comercial de raízes de beterraba e rendimento de grãos verdes do caupi-hortaliça em cultivo solteiro;

$\mathrm{Z}_{\mathrm{bch}}=$ é a proporção do plantio da beterraba em consórcio com caupi-hortaliça;

$\mathrm{Z}_{\text {chb }}=$ é a proporção do plantio do caupi-hortaliça em consórcio com beterraba.

O índice de razão competitiva foi obtido pelas taxas de competição da beterraba $\left(\mathrm{CC}_{\mathrm{b}}\right)$ e do caupi-hortaliça $\left(\mathrm{CC}_{\mathrm{ch}}\right)$, conforme metodologia proposta por Eskandari \& Ghanbari (2010), sendo calculada pelas seguintes expressões:

$C C_{b}=\left[\frac{\left(\frac{Y_{b c h}}{Y_{b}}\right)}{\left(\frac{Y_{c h b}}{Y_{c h}}\right)}\right]\left(\frac{Y_{c h b}}{Z_{b c h}}\right)$ e $C C_{c h}=\left[\frac{\left(\frac{Y_{c h b}}{Y_{c h}}\right)}{\left(\frac{Y_{b c h}}{Y_{b}}\right)}\right]\left(\frac{Y_{b c h}}{Z_{c h b}}\right)$, em que:

$\mathrm{CC}_{\mathrm{b}}$ e $\mathrm{CC}_{\mathrm{ch}}$, são os coeficientes de competição de beterraba e do caupi-hortaliça;

$\mathrm{Y}_{\mathrm{bch}}$ e $\mathrm{Y}_{\mathrm{chb}}=$ são a produtividade comercial das raízes de beterraba e o rendimento de grãos verdes do caupihortaliça, na associação;

$\mathrm{Y}_{\mathrm{b}}$ e $\mathrm{Y}_{\mathrm{ch}}=$ são a produtividade comercial de raízes de beterraba e o rendimento de grãos verdes do caupi-hortaliça, em cultivo solteiro;

$\mathrm{Z}_{\text {bch }}=$ é a proporção do plantio da beterraba, em consórcio com caupi-hortaliça;

$\mathrm{Z}_{\mathrm{chb}}=$ é a proporção do plantio do caupi-hortaliça, em consórcio com beterraba.

O índice de uso eficiente da terra (UET) é definido pela seguinte expressão:

$U E T=\left(\frac{Y_{b c h}}{Y_{b}}\right)+\left(\frac{Y_{c h b}}{Y_{c h}}\right)$, em que:

$\mathrm{Y}_{\mathrm{bch}}=$ produtividade das raízes comerciais de beterraba, em consórcio, com a produtividade de grãos verdes caupihortaliça;

$\mathrm{Y}_{\mathrm{b}}=$ produtividade das raízes comerciais de beterraba solteira;

$\mathrm{Y}_{\mathrm{chb}}=$ produtividade de grãos verdes caupi-hortaliça, em consórcio, com a produtividade das raízes comerciais de beterraba;

$\mathrm{Y}_{\mathrm{ch}}=$ produtividade de grãos verdes caupi-hortaliça solteiro.

Foi realizada a análise univariada de variância para avaliar os dados das culturas e os índices de eficiência do consórcio. O software utilizado na análise foi o SISVAR (Ferreira, 2011). O teste de Tukey foi usado para comparar as médias entre os arranjos espaciais, a 5\% de probabilidade. O procedimento de ajustamento de curvas de regressão foi usado para estimar o comportamento de cada característica ou índice, em função das quantidades de flor-de-seda incorporadas ao solo (Jandel Scientific, 1991).

\section{RESULTADOS E DISCUSSÃO}

\section{Índice de Competição}

Não houve interação significativa entre os arranjos espaciais e as quantidades de flor-de-seda incorporadas ao solo para a cultura da beterraba e caupi-hortaliça, em nenhum dos índices avaliados (Tabela 1 e 2).

Houve comportamento crescente dos índices de perda ou de ganho real de rendimento do sistema, em função do aumento das quantidades de flor-de-seda incorporadas ao solo, obtendo-se valor máximo de 0,27 na quantidade de flor-de-seda de 46,88 $\mathrm{t} \mathrm{ha}^{-1}$, decrescendo a partir desta dose (Figura 2A).

Comportamento crescente, em função das quantidades de flor-de-seda incorporadas, foi relatado para o índice de perda ou ganho real de rendimento da beterraba, constatando-se que, à medida em que se elevam as quantidades de flor-de-seda, aumenta-se esse ganho, obtendo-se valor máximo de 0,26 na quantidade de $65 \mathrm{t} \mathrm{ha}^{-1}$ (Figura 2B). Por outro lado, para o índice de perda ou ganho real de rendimento do caupi-hortaliça, os dados não se ajustaram a nenhuma equação, observando-se valores médios de 0,40 (Figura 2C).

Com base no resultado obtido no índice de ganho real de rendimento do sistema de 0,27 , houve vantagem na consorciação em comparação com o monocultivo, retratando a eficiência da utilização desse sistema de cultivo. Isso por que, quando se encontra nesse índice um valor maior que zero, ocorre uma vantagem acumulada do consórcio em relação ao monocultivo. Porém, quando encontra-se um valor menor que zero ocorre desvantagem.

Para os índices de superação da beterraba e do caupihortaliça, os maiores valores foram observados nas quantidades de flor-de-seda de 65 e 37,89 t ha-1, obtendo-se valores de -0,47 e 0,68, respectivamente (Figura 2D e E). Esse valor positivo obtido no caupi-hortaliça confere a essa cultura a característica de dominante, enquanto o valor negativo registrado para a cultura da beterraba confere a ela a característica de cultura dominada, dentro do consórcio estabelecido.

A relação de dominância estabelecida pelo caupihortaliça, no consórcio, ocorreu porque essa cultura respondeu ao sistema consorciado mais que a da beterraba. Essa informação pode ser confirmada tendo como base as (Figuras 2D e E), em que se observa que o ganho de produção do caupi-hortaliça foi superior ao da beterraba, resultando, portanto, maior índice de superação daquela cultura.

Com relação aos índices dos coeficientes relativos do sistema, da beterraba, do caupi-hortaliça e aos índices de 
razão competitiva da beterraba e do caupi-hortaliça, não foi observada nenhuma função resposta, sendo encontrados valores médios de 1,52, 0,77, 1,99, 0,63 e 1,97, respectivamente.

O resultado encontrado de 1,99 para o coeficiente relativo populacional do caupi-hortaliça mostra que essa cultura produziu mais do que a expectativa, diferentemente do coeficiente relativo populacional da beterraba, que foi de 0,77 , não atendendo às expectativas.

O maior índice de razão competitiva, obtido pelo caupihortaliça, nesse consórcio, deve-se à habilidade competi- tiva que essa cultura exerceu na utilização de recursos naturais como água, luz e nutrientes, maior que a da beterraba.

Com relação aos arranjos espaciais, não foi observada diferença significativa entre os índices de competição testados (Tabelas 3 e 4), exceto no índice de perda ou de ganho real de rendimento da beterraba, com o arranjo 2:2 proporcionando menor perda de produção.

Esses resultados indicaram que não houve interferência dos arranjos espaciais entre as culturas (de beterraba e caupi-hortaliça), ou seja, independentemente do arranjo

Tabela 1: Resumo da análise de variância dos índices de perda ou de ganho real de rendimento do sistema (PGRR $\left.{ }_{\text {sist }}\right)$, da beterraba $\left(\right.$ PGRR $\left._{\mathrm{b}}\right)$, do caupi-hortaliça $\left(\mathrm{PGRR}_{\mathrm{ch}}\right)$ e dos índices de superação da beterraba $\left(\mathrm{IS}_{\mathrm{b}}\right)$ e do caupi-hortaliça (IS ${ }_{\mathrm{ch}}$ ), em função de quantidades de flor-de-seda e dos arranjos espaciais das culturas componentes

\begin{tabular}{lcccccc}
\hline FV & GL & PGRR $_{\text {sist }}$ & PGAR $_{\mathbf{b}}$ & PGAR $_{\text {ch }}$ & IS $_{\mathbf{b}}$ & IS $_{\text {ch }}$ \\
\hline Blocos & 3 & $0,78^{\text {ns }}$ & $0,73^{\text {ns }}$ & $4,67^{*}$ & $0,23^{\text {ns }}$ & $0,23^{\text {ns }}$ \\
Quantidades (Q) & 3 & $1,47^{\text {ns }}$ & $0,27^{\text {ns }}$ & $4,08^{*}$ & $1,60^{\text {ns }}$ & $1,60^{\text {ns }}$ \\
Arranjos (A) & 2 & $0,16^{\text {ns }}$ & $0,03^{\text {ns }}$ & $1,25^{\text {ns }}$ & $0,32^{\text {ns }}$ & $0,32^{\text {ns }}$ \\
Q x A & 6 & $1,07^{\text {ns }}$ & $0,82^{\text {ns }}$ & $2,17^{\text {ns }}$ & $0,66^{\text {ns }}$ & $0,66^{\text {ns }}$ \\
\hline CV $(\%)$ & - & 254,48 & 124,77 & $-100,34$ & 98,03 & $-98,03$ \\
\hline
\end{tabular}

${ }^{*}$ Significativo a $1 \%$ de probabilidade; *Significativo a $5 \%$ de probabilidade; ns Não significativo.

Tabela 2: Resumo da análise de variância dos coeficientes relativos populacionais do sistema $\left(\mathrm{CRP}_{\text {sist }}\right)$, da beterraba $\left(\mathrm{CRP}_{\mathrm{b}}\right)$, do caupi-hortaliça $\left(\mathrm{CRP}_{\mathrm{ch}}\right)$ e dos índices de razão competitiva da beterraba $\left(\mathrm{RC}_{\mathrm{b}}\right)$ e do caupi-hortaliça $\left(\mathrm{RC}_{\mathrm{ch}}\right)$, em função de quantidades de flor-de-seda e dos arranjos espaciais das culturas componentes

\begin{tabular}{lcccccc}
\hline FV & GL & CRP $_{\text {sist }}$ & CRP $_{\mathbf{b}}$ & $\mathbf{C R P}_{\text {ch }}$ & RC $_{\mathbf{b}}$ & $\mathbf{R C}_{\text {ch }}$ \\
\hline Blocos & 3 & $1,25^{\text {ns }}$ & $1,08^{\text {ns }}$ & $0,89^{\text {ns }}$ & $1,15^{\text {ns }}$ & $0,16^{\text {ns }}$ \\
Quantidades (Q) & 3 & $0,30^{\text {ns }}$ & $2,94^{\text {ns }}$ & $0,74^{\text {ns }}$ & $2,28^{\text {ns }}$ & $2,26^{\text {ns }}$ \\
Arranjos (A) & 2 & $0,90^{\text {ns }}$ & $1,54^{\text {ns }}$ & $0,21^{\text {ns }}$ & $1,44^{\text {ns }}$ & $0,87^{\text {ns }}$ \\
Q x A & 6 & $1,82^{\text {ns }}$ & $0,78^{\text {ns }}$ & $1,66^{\text {ns }}$ & $0,30^{\text {ns }}$ & $0,48^{\text {ns }}$ \\
\hline CV $(\%)$ & - & 127,41 & 75,20 & 105,32 & 49,33 & 51,08 \\
\hline
\end{tabular}

${ }^{* *}$ Significativo a $1 \%$ de probabilidade; ${ }^{*}$ Significativo a $5 \%$ de probabilidade; ${ }^{\text {ns Não significativo. }}$

Tabela 3: Valores médios dos índices de perda ou de ganho real de rendimentos do sistema $\left(\mathrm{PGRR}_{\text {sist }}\right)$, da beterraba $\left(\mathrm{PGRR}_{\mathrm{b}}\right)$, do caupi-hortaliça $\left(\right.$ PGRR $\left._{\mathrm{ch}}\right)$ e dos índices de superação da beterraba $\left(\mathrm{IS}_{\mathrm{b}}\right)$ e do caupi-hortaliça $\left(\mathrm{IS}_{\mathrm{ch}}\right)$, do cultivo consorciado de beterraba com caupi-hortaliça, em função de arranjos espaciais das culturas componentes

\begin{tabular}{lccccc}
\hline Arranjos espaciais & PGRR $_{\text {sist }}$ & PGRR $_{\mathbf{b}}$ & PGRR $_{\text {ch }}$ & IS $_{\mathbf{b}}$ & IS $_{\text {ch }}$ \\
\hline $2: 2$ & $0,30 \mathrm{a}$ & $-0,08 \mathrm{a}$ & $0,38 \mathrm{a}$ & $-0,47 \mathrm{a}$ & $0,47 \mathrm{a}$ \\
$3: 3$ & $0,08 \mathrm{a}$ & $-0,22 \mathrm{ab}$ & $0,30 \mathrm{a}$ & $-0,52 \mathrm{a}$ & $0,52 \mathrm{a}$ \\
$4: 4$ & $0,21 \mathrm{a}$ & $-0,30 \mathrm{~b}$ & $0,51 \mathrm{a}$ & $-0,81 \mathrm{a}$ & $0,81 \mathrm{a}$ \\
\hline
\end{tabular}

*Médias seguidas pela mesma letra minúscula na coluna não diferem entre si pelo teste de Tukey a $5 \%$ de probabilidade.

Tabela 4: Valores médios dos coeficientes relativos populacionais do sistema $\left(\mathrm{CRP}_{\text {sist }}\right)$, da beterraba $\left(\mathrm{CRP}_{\mathrm{b}}\right)$, do caupi-hortaliça $\left(\mathrm{CRP}_{\mathrm{ch}}\right)$ e dos índices de razão competitiva da beterraba $\left(\mathrm{RC}_{\mathrm{b}}\right)$ e do caupi-hortaliça $\left(\mathrm{RC}_{\mathrm{ch}}\right)$, do cultivo consorciado de beterraba com caupi-hortaliça, em função de arranjos espaciais das culturas componentes

\begin{tabular}{lccccc}
\hline Arranjos espaciais & $\mathbf{C R P}_{\text {sist }}$ & $\mathbf{C R P}_{\mathbf{b}}$ & $\mathbf{C R P}_{\text {ch }}$ & $\mathbf{R C}_{\mathbf{b}}$ & $\mathbf{R C}_{\text {ch }}$ \\
\hline $2: 2$ & $1,82 \mathrm{a}$ & $1,05 \mathrm{a}$ & $1,91 \mathrm{a}$ & $0,73 \mathrm{a}$ & $1,66 \mathrm{a}$ \\
$3: 3$ & $1,35 \mathrm{a}$ & $0,71 \mathrm{a}$ & $1,58 \mathrm{a}$ & $0,65 \mathrm{a}$ & $1,86 \mathrm{a}$ \\
$4: 4$ & $1,38 \mathrm{a}$ & $0,56 \mathrm{a}$ & $2,47 \mathrm{a}$ & $0,50 \mathrm{a}$ & $2,39 \mathrm{a}$ \\
\hline
\end{tabular}

*Médias seguidas pela mesma letra minúscula na coluna não diferem entre si pelo teste de Tukey a 5\% de probabilidade.

Rev. Ceres, Viçosa, v. 65, n.5, p. 433-442, set/out, 2018 

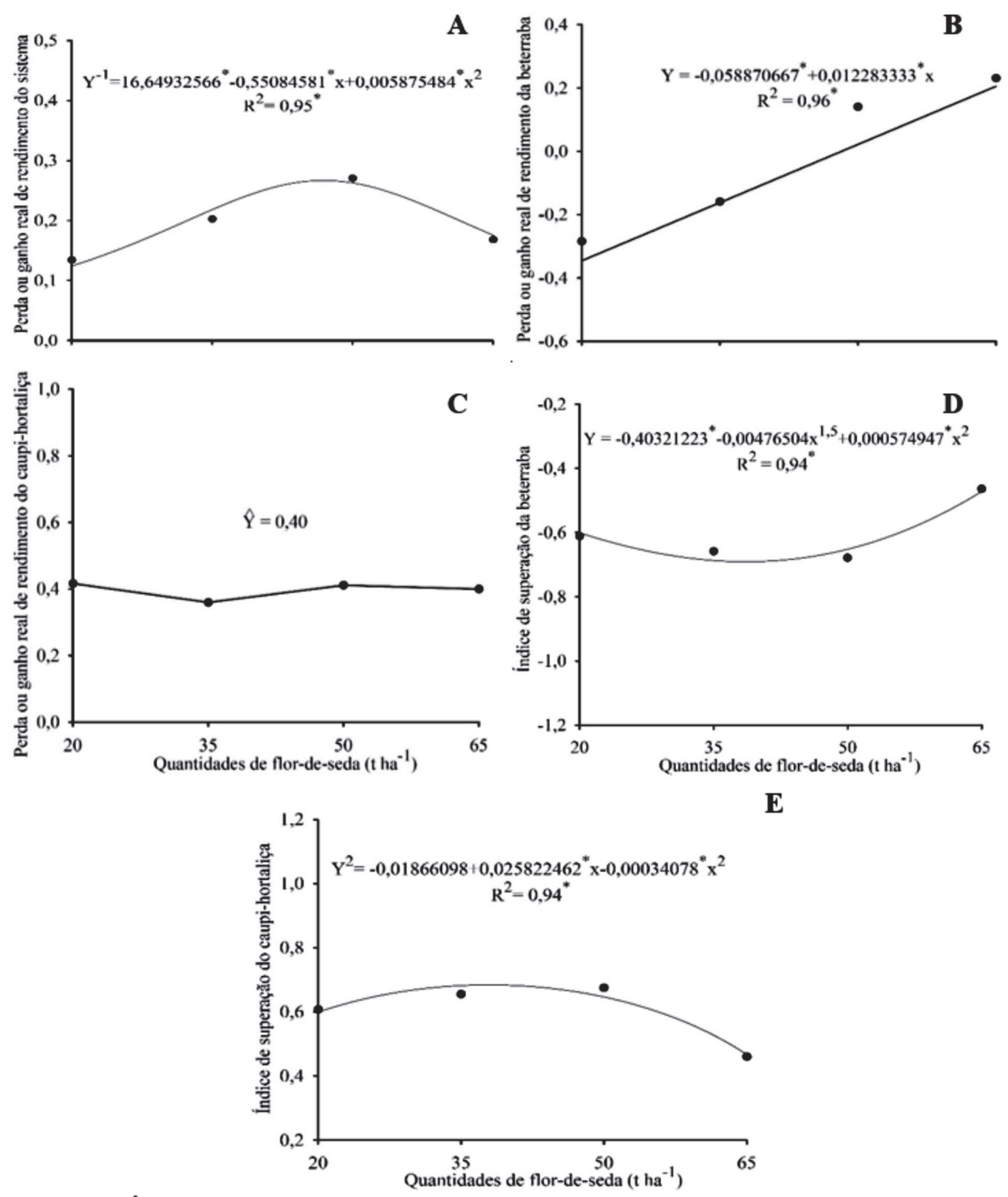

Figura 2: Índices de perda ou de ganho real de rendimento do sistema (A), da beterraba (B), do caupi-hortaliça (C), de superação da beterraba (D) e de superação do caupi-hortaliça (E), do cultivo consorciado de beterraba com caupi-hortaliça em função de quantidades de flor-de-seda incorporadas ao solo.

Tabela 5: Resumo da análise de variância do índice de uso eficiente da terra do sistema $\left(\mathrm{UET}_{\text {sist }}\right)$, da beterraba $\left(\mathrm{UET}_{\mathrm{b}}\right)$ e do caupihortaliça $\left(\mathrm{UET}_{\mathrm{ch}}\right)$, em função de quantidades de flor-de-seda e arranjos espaciais das culturas componentes

\begin{tabular}{lcccc}
\hline FV & GL & $\mathbf{U E T}_{\text {sist }}$ & UET $_{\mathbf{b}}$ & UET $_{\text {ch }}$ \\
\hline Blocos & 3 & $0,90^{\mathrm{ns}}$ & $0,92^{\mathrm{ns}}$ & $0,04^{\mathrm{ns}}$ \\
Quantidades (Q) & 3 & $1,21^{\mathrm{ns}}$ & $3,00^{\mathrm{ns}}$ & $0,26^{\mathrm{ns}}$ \\
Arranjos (A) & 2 & $3,66^{\mathrm{ns}}$ & $3,49^{\mathrm{ns}}$ & $0,80^{\mathrm{ns}}$ \\
Q x A & 6 & $1,12^{\mathrm{ns}}$ & $0,63^{\mathrm{ns}}$ & $0,70^{\mathrm{ns}}$ \\
\hline CV $(\%)$ & - & 29,71 & 29,71 & 35,51 \\
\hline
\end{tabular}

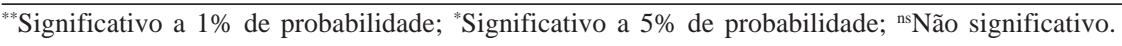



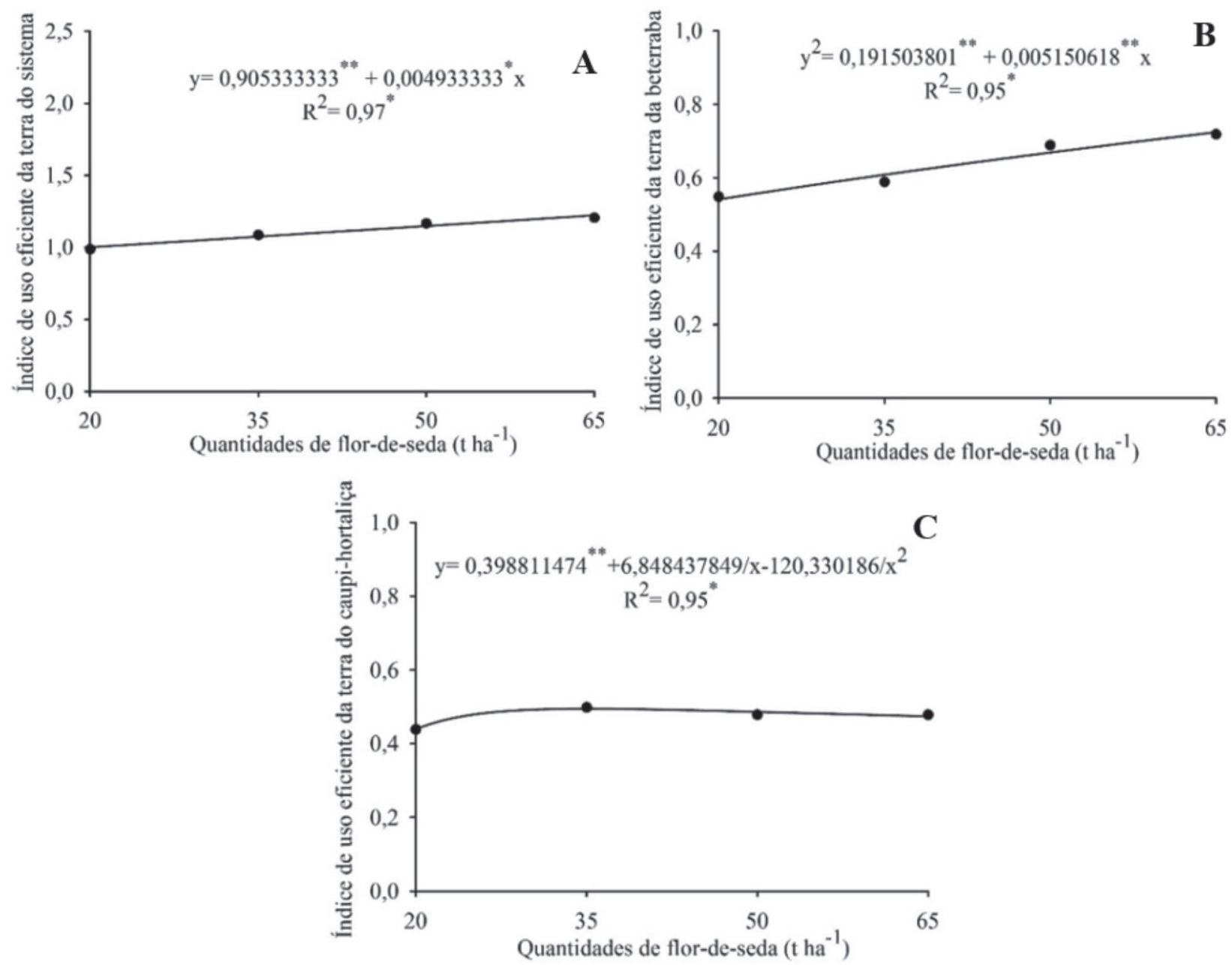

Figura 3: Índices de uso eficiente da terra do sistema (A), da beterraba (B) e do caupi-hortaliça (C), do cultivo consorciado de beterraba com caupi-hortaliça em função de quantidades de flor-de-seda incorporadas ao solo.

espacial utilizado, não haverá alteração da habilidade competitiva das culturas utilizadas no consórcio.

Esse resultado ocorreu, provavelmente, graças à adequada distribuição das plantas no campo, acarretando ótimas altura de plantas e distribuição das folhas no espaço, entre outras características morfológicas, reduzindo-se a competição por energia luminosa (Pinto \& Pinto, 2012).

\section{Eficiência biológica}

Não se observou interação significativa entre os arranjos espaciais e as quantidades de flor-de-seda nos índices de eficiência biológica avaliados (Tabela 5).

Comportamento crescente foi observado no índice de uso eficiente da terra do sistema, UET $_{\text {sist, }}$ e no índice de uso eficiente da terra da beterraba $\mathrm{UET}_{b}$, em função das quantidades de flor-de-seda incorporadas, obtendo-se valores máximos de 1,22 e de 0,72 , respectivamente, na quantidade de flor-de-seda de $65 \mathrm{t} \mathrm{ha}^{-1}$ (Figuras 3A e B).

Para o índice de uso eficiente da terra do caupi-hortaliça $\mathrm{UET}_{\text {ch }}$, houve comportamento crescente, em função das quantidades de flor-de-seda incorporadas, obtendo-se valor máximo de 0,49, na quantidade de flor-de-seda de $35,14 \mathrm{t} \mathrm{ha}^{-1}$, decrescendo a partir desta dose (Figuras 3C).

Os valores máximos encontrados para esses índices, nessas quantidades de flor-de-seda, devem-se provavelmente aos efeitos benéficos proporcionados ao solo por essa adubação, o que favoreceu melhores condições para as culturas associadas.

Entre esses efeitos, encontra-se a diminuição da acidez e do alumínio tóxico (Bezerra Neto et al., 2014). Outro aspecto é que o incremento do teor de matéria orgânica no solo pode reduzir a retenção de fósforo na superfície de alguns minerais de argila, aumentando a sua disponibilidade para as plantas (Favacho et al., 2017).

$\mathrm{O}$ resultado encontrado para uso eficiente da terra (UET), de 1,22, mostra o efeito positivo na produção de alimentos, por unidade de área, desse sistema de cultivo, quando comparado com o cultivo solteiro. Isto significa que são necessários pelo menos $22 \%$ a mais de área para que as culturas, no plantio solteiro, produzam o equivalente à produção do consórcio, em um hectare. 
Tabela 6: Valores médios dos índices de uso eficiente da terra do sistema $\left(\mathrm{UET}_{\text {sist }}\right)$, da beterraba $\left(\mathrm{UET}_{\mathrm{b}}\right)$ e do caupi-hortaliça $\left(\mathrm{UET}_{\mathrm{ch}}\right)$, do cultivo consorciado de beterraba com caupi-hortaliça, em função de arranjos espaciais das culturas componentes

\begin{tabular}{llll}
\hline Arranjos espaciais & UET $_{\text {sist }}$ & UET $_{\mathbf{b}}$ & UET $_{\mathbf{c h}}$ \\
\hline $2: 2$ & $1,16 \mathrm{a}$ & $0,69 \mathrm{a}$ & $0,47 \mathrm{a}$ \\
$3: 3$ & $1,03 \mathrm{a}$ & $0,59 \mathrm{a}$ & $0,44 \mathrm{a}$ \\
$4: 4$ & $1,05 \mathrm{a}$ & $0,53 \mathrm{a}$ & $0,52 \mathrm{a}$ \\
\hline
\end{tabular}

*Médias seguidas pela mesma letra minúscula na coluna não diferem entre si pelo teste de Tukey a 5\% de probabilidade.

Não se observou diferença significativa entre os arranjos espaciais para os índices de uso eficiente da terra do sistema $\mathrm{UET}_{\text {sist }}$, da beterraba $\mathrm{UET}_{\mathrm{b}}$ e do caupi-hortaliça $\mathrm{UET}_{\text {ch }}$ (Tabela 6).

No entanto, independentemente de ter havido ou não diferença significativa entre os arranjos espaciais utilizados para o uso eficiente da terra sistema $\left(\mathrm{UET}_{\text {sist. }}\right)$, os resultados encontrados na presente pesquisa com valores maiores que uma unidade, expressa maior viabilidade agronômica do sistema de cultivo consorciado do que o monocultivo.

Os maiores valores médios foram registrados no arranjo 2:2, corroborando com os obtidos por Favacho et al. (2017), que, ao estudarem as eficiências produtiva e econômica do consórcio de cenoura com caupi proveniente de adubação verde e os arranjos espaciais, não observaram diferença significativa entre os arranjos espaciais, com os maiores valores médios registrados no arranjo 2:2, para os índices agroeconômicos.

\section{CONCLUSÕES}

O caupi-hortaliça foi mais competitivo no sistema consorciado que a beterraba.

A maior eficiência do consórcio de beterraba com caupi-hortaliça foi obtida na quantidade de $65 \mathrm{t} \mathrm{ha}^{-1} \mathrm{de}$ biomassa de flor-de-seda incorporada ao solo.

Não houve influência dos arranjos espaciais na habilidade competitiva e biológica do consórcio de beterraba com caupi-hortaliça.

\section{REFERÊNCIAS}

Andrade Filho FC (2014) Bicultivo de folhosas consorciadas com beterraba em função de adubação com flor-de-seda e densidades populacionais. Tese de Doutorado. Universidade Federal Rural do Semi-Árido, Mossoró. 94p.

Batista TMV, Bezerra Neto F, Porto VCN, Barros Junior AP, Silva IN, Silva ML, Lima JSS \& Oliveira EQ (2016) Bio-agroeconomic returns from carrot and salad rocket as intercropsusing hairy woodrose as green manure in a semi-arid region of Brazil. Ecological Indicators, 67:458-465.

Bezerra Neto F, Oliveira LJ, Santos AP, Lima JSS \& Silva ÍN (2014) Otimização agroeconômica da cenoura fertilizada com diferentes doses de jitirana. Ciência Agronômica, 45:305311 .
Bezerra Neto F, Porto VCN, Gomes EG, Cecilio Filho AB, Moreira JN (2012) Assessment of agroeconomic indices in polycultures of lettuce, rocket and carrot through uni - and multivariate approaches in semi-arid Brazil. Ecological Indicators, 14:1117.

Bezerra Neto F, Gomes EG \& Oliveira AM (2007) Produtividade biológica em sistemas consorciados de cenoura e alface avaliada através de indicadores agroeconômicos e métodos multicritério. Horticultura Brasileira, 25:193-198.

Cecílio Filho AB, Bezerra Neto F, Rezende BLA, Barros Junior AP \& Lima JSS (2015) Indices of bio-agroeconomic efficiency in intercropping systems of cucumber and lettuce in greenhouse. Australian Journal of Crop Science, 9:1154-1164.

Cecílio Filho AB, Bezerra Neto F, Rezende BLA, Grangeiro LC \& Lima JSS (2013) Indices of competition and bio-agroeconomic efficiency of lettuce and tomato intercrops in greenhouses. Australian Journal of Crop Science, 7:809-819.

Eskandari H \& Ghanbari A (2010) Environmental resource comsumption in wheat (Triticum aestivum) and bean (Vicia faba) intercropping: comparison of nutrient uptake and light interception. Notulae Scientia Biologicae, 2:100-103.

Favacho FS, Lima JSS, Bezerra Neto F, Silva JN \& Barros Júnior AP (2017) Eficiência produtiva e econômica do consórcio de cenoura x caupi proveniente de adubação verde e arranjos espaciais. Revista Ciência Agronômica, 48:337-346.

Ferreira DF (2011) Sisvar: a computer statistical analysis system. Ciência e Agrotecnologia, 35:1039-1042.

Jandel Scientific (1991) Table curve: curve fitting software. Corte Madera, Jandel Scientific. 280p.

Lima FS, Beltrão NEM, Oliveira FA, Pereira WE \& Sousa CS (2008) Épocas relativas de plantio e adubação nitrogenada: índices agroeconômicos do algodoeiro consorciado com gergelim. Revista Ciência Agronômica, 39:555-561.

Lima JSS, Bezerra Neto F, Negreiro MZ, Ribeiro MCC \& Barros Júnior AP (2010) Productive performance of carrot and rocket cultivars in strip-intercropping system and sole crops. Agrociencia, 44:561-574.

Linhares PCF, Pereira MFS, Assis JP \& Bezerra AKH (2012) Quantidades e tempos de decomposição da jitirana no desempenho agronômico do coentro. Ciência Rural, 42:243-248.

Oliveira EQ, Bezerra Neto F, Negreiros MZ \& Barros Júnior AP (2004) Desempenho agroeconômico do bicultivo de alface em sistema solteiro e consorciado com cenoura. Horticultura Brasileira, 22:712-717.

Oseni TO \& Aliyu IG (2010) Effect of row arrangements on sorghum-cowpea intercrops in the semi-arid savannah of Nigeria. International Journal of Agriculture and Biology, 12:137-140.

Pinto CM \& Pinto ORO (2012) Avaliação da eficiência biológica e habilidade competitiva nos sistemas de consorciação de plantas. Enciclopédia Biosfera, 8:105-122. 
Pinto CM, Pinto ORO \& Pitombeira JB (2012) Mamona e girassol no sistema de consorciação em arranjo de fileiras: habilidade competitiva. Revista Brasileira de Agropecuária Sustentável, 2:103-113

Pivetta LG, Guimarães VF, Fioreze SL, Pivetta LA \& Castoldi G (2012) Avaliação de híbridos de girassol e relação entre parâmetros produtivos e qualitativos. Revista Ciência Agronômica, 43:561-568.

Santos CAF (2011) Cultivares de feijão-caupi para o Vale do São Francisco. Petrolina, Embrapa Semiárido. 10p. (Circular técnica, 94).

Silva JN, Bezerra Neto F, Lima JSS, Rodrigues GSO, Barros Júnior AP \& Chaves AP (2017) Combinations of coriander and salad rocket cultivars in bicropping systems intercropped with carrot cultivars. Revista Caatinga, 30:125-135.
Silva ML, Bezerra Neto F, Linhares PCF \& Bezerra AKH (2013) Produção de cenoura fertilizada com flor-de-seda (Calotropis procera (Ait.) R.Br.). Ciência Agronômica, 44:732-740.

Silva ML, Bezerra Neto F, Linhares PCF, Sá JR, Lima JSS \& Barros Júnior AP (2011) Produção de beterraba fertilizada com jitirana em diferentes doses e tempos de incorporação ao solo. Revista Brasileira de Engenharia Agrícola e Ambiental, 15:801-809.

Silva MG, Sharma RD, Junqueira AMR \& Oliveira CM (2006) Efeito da solarização, adubação química e orgânica no controle de nematoides em alface sob cultivo protegido. Horticultura Brasileira, 24:489-494. 